\title{
Organic/inorganic nanocomposite gels employed as electrolyte supports in Dye-sensitized Photoelectrochemical cells
}

\author{
Elias Stathatos and Panagiotis Lianos ${ }^{\dagger}$ \\ Engineering Science Dept., University of Patras, 26500 Patras, Greece
}

\begin{abstract}
Dye-sensitized photoelectrochemical cells based on $\mathrm{TiO}_{2}$ mesoporous films, a ruthenium bipyridyl derivative as photosensitizer and $\mathrm{a} \mathrm{SiO}_{2} /$ poly(ethylene glycol)-200 nanocomposite thin film as electrolyte support, have been constructed. $\mathrm{TiO}_{2}$ films have been deposited on conductive transparent IndiumTin Oxide glass slides by means of a sol-gel procedure carried out in reverse-micellar solutions. The photosensitizer has been adsorbed on titania films from ethanolic solutions while the electrolyte layer has been synthesized by a sol-gel procedure. The presence of silica in the nanocomposite electrolyte gel provides the gelifying agent, the compound that holds the cell together in a sandwich form and the sealing agent that protects the cell and secures its long-term function. PEG-200 makes the organic subphase which provides the ionic conductivity. The present work describes the construction of the cell and the study of its efficiency. A variant of the cell has also been made by incorporating $\mathrm{Ag}^{+}$and $\mathrm{Ru}^{3+}$ ions into titania particles, but these dopants did not improve cell efficiency, either in their oxidized or in their reduced form.
\end{abstract}

\section{INTRODUCTION}

Dye sensitized photoelectrochemical cells (DSPEC) are studied with increasing interest by several groups around the world [1-11], ever since the original work of Graetzel [1], where it was announced that visible light can be efficiently converted into electricity using mesoporous titania films and a tris(2,2'-bipyridine) ruthenium derivative as photosensitizer. The original DSPEC's employed a liquid electrolyte containing the $\mathrm{I}_{3}{ }^{-} / \mathrm{I}^{-}$redox couple, which is a standard choice $[1,12-$ 15] when combined with $\mathrm{TiO}_{2}$ and Ru-bipyridyl photosensitizers. Most recent efforts are directed towards the choice of a solid electrolyte [5] since liquid electrolytes present many practical disadvantages. On the contrary, a solid electrolyte allows for a sandwich thin film configuration, which is ideal for most applications. In the present work we present a sol-gel procedure for the deposition of a nanocomposite inorganic/organic thin film, combining silica and poly(ethylene glycol)$200\left(\mathrm{SiO}_{2} / \mathrm{PEG}-200\right)$, enriched with $\mathrm{I}_{3}{ }^{-} / \mathrm{I}^{-}$, which supports a solid sandwich thin film DSPEC. The sol-gel procedure is ideal for this application, since in the original sol (liquid) phase, the material can enter into the pores of the mesoporous semiconductor and greatly increase the interface between the semiconductor and the electrolyte.

\section{EXPERIMENTAL}

Titanium (IV) isopropoxide, tetramethoxysilane (TMOS), polyoxyethylene(10) isooctylphenyl ether (Triton X-100),

\footnotetext{
†E-mail: lianos@upatras.gr
}

poly(ethylene glycol)-200 (PEG-200), were purchased from Aldrich and used as received. Cis-bis(isothiocyanato)bis(2,2'-bipyridyl-4,4' -dicarboxylato)-ruthenium (II) [16] $\left(\mathrm{RuL}_{2}(\mathrm{NCS})_{2}\right)$ was provided by Solaronix SA (rue de l'Ouriette 129, 1170 Aubonne VD, Switzerland). The rest of the reagents were from Merck, while Millipore water was used in all experiments. Optically transparent electrodes (OTE) were cut from an indium-tin-oxide (ITO) coated glass $(<10 \mathrm{Ohm} /$ square) purchased from Pilkington-Flabeg, Germany.

2.1. Preparation of $\mathrm{TiO}_{2}$ mesoporous films deposited on OTE-ITO glasses and adsorption of the photosensitizer. A reverse micellar solution of $0.2 \mathrm{M}$ Triton X-100 and $0.4 \mathrm{M}$ water was prepared in cyclohexane. To this solution we added $0.2 \mathrm{M}$ titanium isopropoxide under vigorous stirring and at ambient conditions. Other concentrations of the above components have also been tried but optimal results were obtained with the present combination [17]. Hydrolysis and condensation of titanium isopropoxide begins as soon as it is introduced in the reverse micellar solution, but it takes about an hour before the solution becomes a visible gel $[17,18]$. The thus prepared composite material can be deposited as thin film on an ITO slide by dipcoating. A slide $20 \times 30 \mathrm{~mm}$ was cut from an ITO glass, it was sonicated for $20 \mathrm{~min}$ in ethanol and was, finally, copiously washed with millipore water and dried in a stream of $\mathrm{N}_{2}$. Then it was dipped into the gelling solution at an early stage of gelation and was fast withdrawn at a speed of $2 \mathrm{~cm} / \mathrm{s}$. The composite organicinorganic film was left to dry in air and the dipping was repeated two more times. The film was deposited on only the ITO-side of the glass. The other side was 
covered with a tape. After the three dippings, the back tape was pealed off and the glass surface was locally washed with acetone. Then the film was slowly heated in air, up to $450^{\circ} \mathrm{C}$, at a rate of $7^{\circ} \mathrm{C} / \mathrm{min}$. The film was finally sintered at $450{ }^{\circ} \mathrm{C}$ for about 15 more minutes. The procedure was repeated two additional times so that $3 \times 3$ depositions were made. Its thickness was measured by profilometry and was found $1.2 \mu \mathrm{M}$. The obtained film was transparent. Thicker films could be made by further successive coatings, however, thickness grows at the expense of transparency. AFM and SEM images of the films prepared by the above method and published in previous publications [17-20], reveal a mesoporous structure that consists of $\mathrm{TiO}_{2}$ nanoparticles of practically monodispersed size with exceptional reproducibility. The size of the nanoparticles can be easily controlled by choosing the water/surfactant ratio in the original reverse micellar solution $[17,19]$. Larger nanoparticles are made when more water exists in the solution. The advantage of the reverse-micellar route in making $\mathrm{TiO}_{2}$ particles, as compared with other methods, exactly lies on this capacity to control the mesoporous structure of the obtained films. The diameter of the nanoparticles employed in the present work, as estimated by using AFM images, was around $30 \mathrm{~nm}$. X-ray diffusion study of $\mathrm{TiO}_{2}$ powder made with the above procedure showed that films consist of anatase nanocrystals. When the $\mathrm{TiO}_{2}$ film was taken out of the oven and while it was still hot, it was dipped into an $1 \mathrm{mM}$ ethanolic solution of $\left(\mathrm{RuL}_{2}(\mathrm{NCS})_{2}\right)$ and was left there for about 24 hours. Then it was copiously washed with ethanol, dried in a stream of $\mathrm{N}_{2}$ and studied by absorption spectrophotometry. The dye is steadily attached on the $\mathrm{TiO}_{2}$ film, obviously, by means of its carboxylate groups. Figure 1 shows the absorption spectra of the $\mathrm{TiO}_{2}$ film with and without the adsorbed dye. The absorption of visible light by the film is, obviously, possible only through the dye. The oscillating part in the $\mathrm{TiO}_{2}$ absorption spectrum is due to interference fringes.

2.2. Synthesis of the nanocomposite $\mathrm{SiO}_{2} / \mathrm{PEG}-200$ film containing electrolyte. On the top of the $\mathrm{TiO}_{2}$ /dye layer, a thin composite organic/inorganic film containing $\mathrm{I}_{3}{ }^{-} / \mathrm{I}^{-}$has been deposited under the following procedure, which was carried out at ambient conditions. TMOS was partially hydrolyzed by mixing with acidified water $(\mathrm{HCl}, \mathrm{pH} 3.0)$ at a molar ratio TMOS: water $=1: 2$. The mixture was stirred for one hour. It was originally turbid but it became clear in the course of proceeding hydrolysis. Then to $1 \mathrm{ml}$ of this sol, we added $5 \mathrm{~g}$ of an aqueous PEG-200 solution containing the redox-couple. In particular, $\mathrm{I}_{2}$ was diluted in pure PEG-200 while KI was diluted in water. Then the two solvents were mixed and produced a transparent solution. Only if $\mathrm{I}_{2}$ is first diluted in PEG-200, it can finally produce a transparent solution, since it is not directly

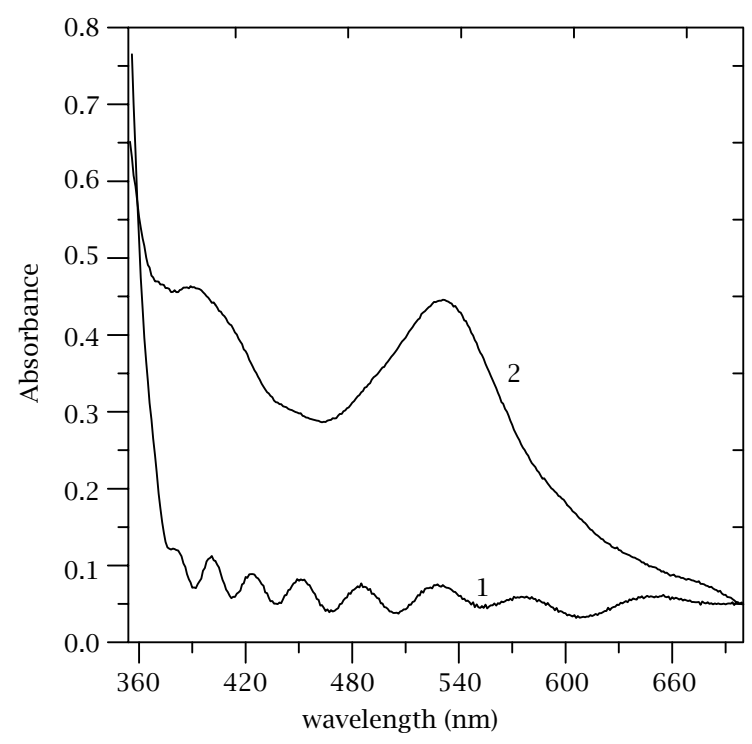

Figure 1. (1) Absorption spectrum of a standard $\mathrm{TiO}_{2}$ film on a glass support. (2) Same film with adsorbed dye.

soluble in water. Different PEG-200/water ratios have been obtained for the purpose of the present work, while the overall concentration was $0.03 \mathrm{M}$ for $\mathrm{I}_{2}$ and $0.3 \mathrm{M}$ for KI. After mixing with prehydrolyzed TMOS, the solution was stirred for 4 hours, when it was judged ready for application. During that time, a condensation procedure goes on by $-\mathrm{Si}-\mathrm{O}-\mathrm{Si}-$ polymerization, slowly producing a gel. 4 hours of waiting time under stirring still leaves the solution at an early stage of gelation. A thin film of this composite material was deposited by dip-coating. As before, the back inactive side of the glass support was covered with a tape before dipping and was pealed off afterwards.

2.3. Application of the counter-electrode that ends the fabrication of the cell. On the top of the $\mathrm{SiO}_{2} / \mathrm{PEG}-200 /$ electrolyte layer, while the electrolyte layer was still in the fluid phase, we placed an ITO electrode covered with a thin Pt film and pressed against the underlying support. $-\mathrm{Si}-\mathrm{O}$ - bridges help binding the counter electrode so that the composite $\mathrm{SiO}_{2} / \mathrm{PEG}^{-}$ 200 material additionally acts in holding the parts of the cell together in a stable thin sandwich configuration. Pt was applied prior to cell binding by vacuum evaporation on the ITO slide. Its presence is necessary to improve cell performance. A schematic diagram of the cell cross section is shown in Figure 2.

Absorption measurements were made with a Cary 1E spectrophotometer. Incident Photon to Current Efficiency (IPCE\%) values [21] have been measured by illumination of the samples with a 250 Watt Phillips tungsten halogen lamp through a filter monochromator (Oriel-7155). The lamp spectrum satisfactorily simulates solar radiation at the surface of the earth. The 


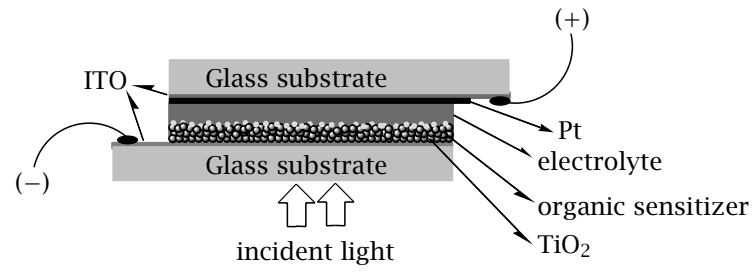

Figure 2. Schematic diagram of a cell section.

number of incident photons was calculated by employing a radiant power/energy meter (Oriel-70260).

\section{RESULTS AND DISCUSSION}

$\mathrm{SiO}_{2} /$ PEG nanocomposite materials belong to the socalled Class I organic/inorganic nanocomposites [22, 23]. They form two interpenetrating subphases which are held together by weak forces ensuing from hydrogen bonds or Van der Waals forces. The existence of the silica (inorganic) subphase is obvious from the fact that the materials are solid gels and this can come only from a silica network, since there exists no other solidifying agent in these mixtures. The existence of the organic subphase has been demonstrated by fluorescence probe measurements [11, 24]. PEG oligomers, as the PEG-200 presently used, are liquids and they are known to be ionic conductors [25, 26]. When a salt is disolved in PEG, the cations are bound by the ether oxygens by coordinating several PEG chains [27]. Conductivity is mainly carried on by anions [26] and this fact is especially in favour of the presently used redox couple $\mathrm{I}_{3}{ }^{-} / \mathrm{I}^{-}$. When PEG is transferred into a sol-gel matrix of the Class I nanocomposite structure, ionic conductivity is preserved to a rather high value at ambient conditions $\left(\sigma \cong 6 \times 10^{-2} \mathrm{~S} \cdot \mathrm{cm}^{-1}\right.$ [28]). $\mathrm{SiO}_{2} / \mathrm{PEG}$ nanocomposites are stable materials. Their stability has recently led to conclusions that the forces holding together the two subphases should not be so weak as it has been so far accepted. Thus recent works talk of strong bonds between the two subphases [29, 30]. It has even been suggested that covalent bonds can be formed between the two subphases during the solgel process [30]. In any case, Class I materials are distinguished from Class II hybrids, where the covalent bond already exists in the precursor compound [22, 23]. Class II materials are currently studied in our laboratory [31].

The above nanocomposite gels seem then to be appropriate materials to be applied to DSPEC's. We have constructed such cells and have studied their performance. The first question to be answered in the employment of such materials, is to decide about the percentage of each subphase in the gel. $\mathrm{SiO}_{2}$ and PEG-200 can be mixed in any proportion. The stability of the cell is higher if the quantity of silica is higher. However, as the silica percentage increases, the ionic conductivity of the gel decreases. This problem was treated in a previous work [11] and it was found that an optimum combination of the two subphases should include just enough PEG-200 to form a percolating cluster. A percolating cluster for the organic subphase provides enough conductivity and sufficient quantity of silica to stabilize the cell. We have then worked with 10\% w PEG-200, a quantity that is just above the percolation threshold [11]. The efficiency of the cell is expressed in terms of the maximum IPCE\% value [21],

$$
\mathrm{IPCE} \%=\frac{1240 \times \mathrm{I}\left(\mu \mathrm{A} / \mathrm{cm}^{2}\right)}{\lambda \mathrm{nm} \times \mathrm{P}_{\text {inc }}\left(\mathrm{W} / \mathrm{m}^{2}\right)},
$$

where $P_{\text {inc }}$ is the incident light power at the wavelength $\lambda$ and I the produced photocurrent. IPCE\% thus gives the percentage of the number of electrons produced with respect to the number of photons absorbed. Maximum IPCE\% is located very close to the wavelength corresponding to the maximum of absorption of the dye sensitizer. Indeed, as seen in Figure 3, presenting IPCE\% values at different illumination wavelengths together with dye absorption spectrum, the maximum of cell efficiency practically coincides with the maximum of dye absorption. This is a sound demonstration of the dyesensitization process. It should be noted at this point that the measured IPCE\% values are in fact lower limits and the actual values should be larger if the real number of absorbed photons were known. As seen in Figure 1, the maximum optical density of the photosensitizer is around 0.4 , which means that only $60 \%$ of the incident

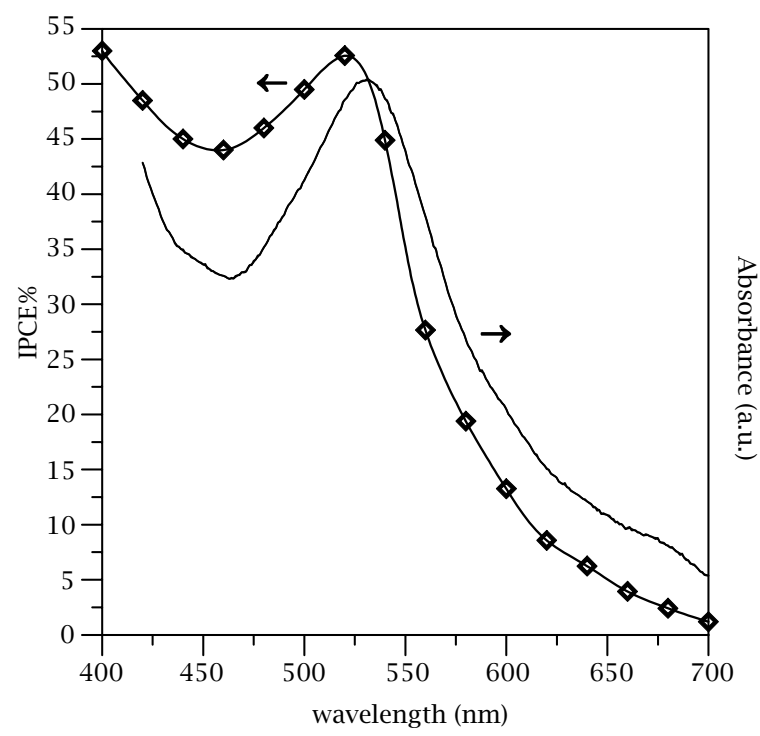

Figure 3. IPCE\% values and adsorbed-dye absorbance vs. illumination wavelength. $T=25^{\circ} \mathrm{C}$. PEG-200 content was $10 \% w$. 
photons are absorbed. In fact light is further absorbed by reflection on the counter-electrode. Since IPCE\% is calculated under the assumption that all incident photons are absorbed by the dye, the recorded IPCE\% values are obviously underestimated. The performance of the cell is seen in the I-V curve of Figure 4. By illumination with diffuse light of $96 \mathrm{~mW} / \mathrm{cm}^{2}$ (about AM 1.5) the open circuit voltage was $0.47 \mathrm{~V}$ and the short circuit current was $4.34 \mathrm{~mA} / \mathrm{cm}^{2}$. This is a very satisfactory result and there is ground for further improvement. One of the factors currently studied in our laboratory is to reduce the amount of water involved in the sol providing the nanocomposite gel. We believe that cell performance will be improved if water is completely eliminated.

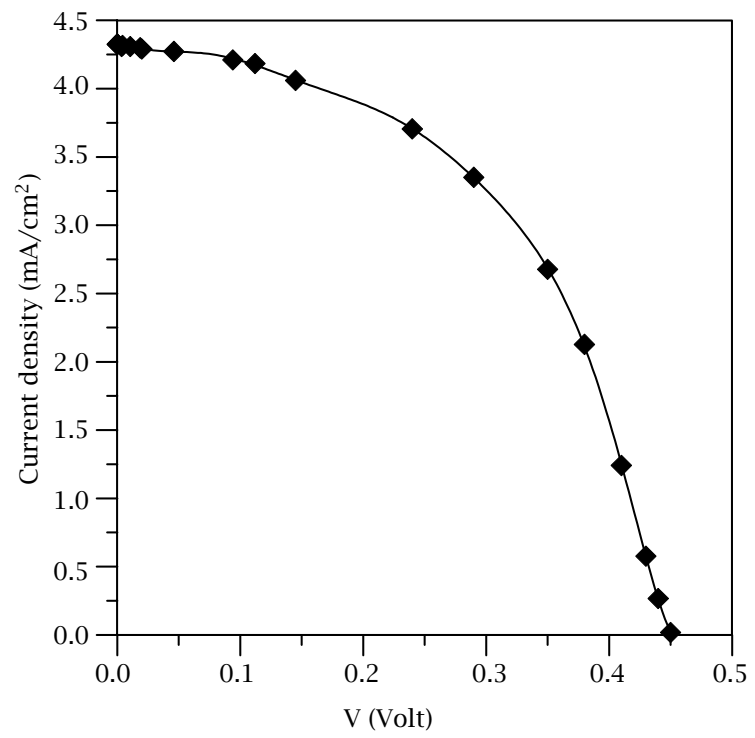

Figure 4. I-V curve for a cell made with $10 \% w$ PEG. Illumination was made by white light of $96 \mathrm{~mW} / \mathrm{cm}^{2}$ (about AM1.5 or 1 solar). $T=25^{\circ} \mathrm{C}$.

We have also examined the possibility to dope $\mathrm{TiO}_{2}$ particles with metal ions, such as $\mathrm{Ru}^{3+}$ or $\mathrm{Ag}^{+}$. These ions have been introduced as salts in the water used to make the original reverse micelles and in this manner they are incorporated into the titania structure. The obtained films were used in two different variants: (1) after the mesoporous titania films were taken out of the oven they were immediately immersed into the solution containing photosensitiser; (2) in the second variant, fresh titania films were submitted to UV radiation in order to reduce ions by electrons created by titania absorption of UV photons [32, 33] and then they were immersed to adsorb photosensitizer. The idea to incorporate metal dopants comes from other studies were titania is used as a catalyst for photodegradation [33] and where the presence of dopants enhances its photocatalytic activity. Noble metals, in particular, silver have been used for this goal. Silver increases the photocatalytic capacity of titania by some different physical mechanisms that may act separately or simultaneously. Reduced silver particles of colloidal dimension (metallic silver) are considered to be electron scavengers. Thus by trapping electrons produced in electron-hole pairs after photons absorption, they prevent electron-hole recombination [34]. Plasmon resonance effects in metallic silver nanoparticles are also held responsible for local enhancement of the electric field, facilitating electron-hole pair production and separation [35-37]. Finally, silver is also reported to affect the structure of titania, leading to modification of its photocatalytic activity [38]. In view of these phenomena, we have examined the role of the presence of metal dopants in DSPEC's. Some of the obtained data are tabulated in Table 1. The presence of metals did not improve the performance of the cells, both in the reduced and in the oxidized form. In the case of ruthenium, its presence was detrimental, dropping cell performance to a practical zero. Ag caused a small decrease in cell performance but it offered higher open circuit voltage by an important percentage. Silver then may be interesting in cases where cell voltage is of importance. It is not clear why the presence of these dopants decreases cell performance. It is generally accepted that surface plasmon resonance effects induced by silver particles increases optical absorption and photoluminescence of dyes [39]. This holds true for Ru-bipyridyl derivatives [40], therefore, it is expected that silver should increase the performance of DSPEC's [39]. Nevertheless, it has also been reported that for $\mathrm{TiO}_{2}$ electrodes with dispersed silver particles, the photoresponse of a dye-sensitized film may in some cases increase and in other cases decrease, in the presence of the metal particles $[36,41]$. The factors that favor increase are the above mentioned surface plasmon resonance effects and the facilitation of hole transport to the surface of the semiconductor and subsequent transfer to the surrounding electrolyte, in the presence of metal particles [36]. However, other simultaneously operating factors decrease photocurrent by decreasing mobility of charge carriers due to Schottky barriers, by providing traps for electron-hole recombination and by retarding electron transfer due to fluctuations of the band edge in the presence of metal particles [36]. In our case, it seems that the unfavorable factors prevail and we believe that this is due to the fact that metal particles are too finely dispersed to offer important surface plasmon resonance effects. Indeed no such band has been detected in the corresponding absorption spectra [33]. The fact that reduced species (after UV illumination) offer a rather increased photoconversion response (cf. Table 1) points to the same direction. This question is further studied in our laboratory. 
Table 1. Cell efficiency data for pure and metal doped titania.

\begin{tabular}{lccc}
\hline Metal dopant & Short-circuit current $I_{\mathrm{Sc}}\left(\mathrm{mA} / \mathrm{cm}^{2}\right)$ & Open-circuit voltage $V_{\mathrm{oc}}$ (volt) & Over-all efficiency $\eta(\%)$ \\
\hline Pure $\mathrm{TiO}_{2}$ & 4.34 & 0.47 & 2.2 \\
$\mathrm{Ag}$ & 2.57 & 0.63 & 1.71 \\
$\mathrm{Ag}$ treated under UV & 2.69 & 0.62 & 1.75 \\
$\mathrm{Ru}$ & 0.15 & 0.44 & 0.073 \\
$\mathrm{Ru}$ treated under UV & 0.17 & 0.46 & 0.074 \\
\hline
\end{tabular}

\section{ACKNOWLEDGEMENT}

We acknowledge financial aid from the program "KAPA@EO $\triangle \Omega P H \Sigma$." of the University of Patras and the program: "Management of Industrial Wastes"of the Greek General Secretariat of Research and Technology.

\section{References}

[1] B. O’Reagan and M. Graetzel, Nature 353 (1991), 737.

[2] K. Kalyanasundaram and M. Graetzel, Coordination Chemistry Reviews 177 (1998), 347.

[3] A. T. Heimer, A. C. Bignozzi, and J. G. Meyer, J. Phys. Chem. 97 (1993), 11987.

[4] F. Cao, G. Oskam, and C. P. Searson, J. Phys. Chem. 99 (1995), 17071.

[5] M. Matsumoto, H. Miyazaki, K. Matsuhiro, Y. Kumashiro, and Y. Takaoka, Solid State Ionics $\mathbf{8 9}$ (1996), 263.

[6] S. Ferrere, A. Zaban, and A. B. Gregg, J. Phys. Chem. B 101 (1997), 4490.

[7] M. Alebbi, A. C. Bignozzi, A. T. Heimer, M. G. Hasselmann, and J. G. Meyer, J. Phys. Chem. B 102 (1998), 7577.

[8] K. Tennakone, G. K. R. Senadeera, V. P. S. Perera, I. R. M. Kottegoda, and L. A. A. De Silva, Chem. Mater. 11 (1999), 2474.

[9] N.-G. Park, J. van de Lagemaat, and A. J. Frank, J. Phys. Chem. B 104 (2000), 8989.

[10] M. M. Gomez, J. Lu, J. L. Solis, E. Olsson, A. Hagfeldt, and C. G. Granqvist, J. Phys. Chem. B 104 (2000), 8712.

[11] E. Stathatos, P. Lianos, and C. Krontiras, J. Phys. Chem. B, in press.

[12] M. K. Nazeeruddin, A. Kay, I. Rodicio, R. HumphryBaker, E. Mueller, P. Liska, N. Vlachopoulos, and M. Graetzel, J. Am. Chem. Soc. 115 (1993), 6382.

[13] I. Bedja, P. V. Kamat, X. Hua, A. G. Lappin, and S. Hotchandani, Langmuir 13 (1997), 2398.

[14] R. Vogel, K. Hoyer, and H. Weller, J. Phys. Chem. 98 (1994), 3183.

[15] S. K. Deb, R. Ellingson, S. Ferrere, A. J. Frank, B. A. Gregg, A. J. Nozik, N. Park, and G. Schlichthoerl, Paper presented in the 2nd world conference and excibition on photovoltaic solar energy conversion, Vienna, Austria, 1996.

[16] P. Liska, N. Vlachopoulos, M. K. Nazeeruddin, P. Comte, and M. Graetzel, J. Am. Chem. Soc. 110 (1988), 3686.

[17] E. Stathatos, P. Lianos, F. DelMonte, D. Levy, and D. Tsiourvas, Langmuir 13 (1997), 4295.

[18] E. Stathatos, P. Lianos, F. DelMonte, D. Levy, and D. Tsiourvas, J. Sol-Gel Sci. and Tech. 10 (1997), 83.

[19] E. Stathatos, D. Tsiourvas, and P. Lianos, Colloids and Surfaces A. 149 (1999), 49.

[20] E. Stathatos, P. Lianos, and S. Couris, Appl. Phys. Letters 75 (1999), 319.

[21] V. Bach, D. Lupo, P. Comte, J. E. Moser, F. Weissoertel, J. Salbeck, H. Spreitzer, and M. Graetzel, Nature 395 (1998), 583.

[22] P. Judeinstein and C. Sanchez, J. Mater. Chem. 6 (1996), 511.

[23] P. Lesot, S. Chapuis, J.-P. Bayle, J. Rault, E. Lafontaine, A. Campero, and P. Judeinstein, J. Mater. Chem. 8 (1992), 147.

[24] V. Bekiari, M. Ferrer, E. Stathatos, and P. Lianos, J. Sol-Gel Sci. Techn. 13 (1998), 95.

[25] H. Cai and G. C. Farrington, J. Electrochem. Soc. 139 (1992), 744.

[26] M. S. Mendolia and G. C. Farrington, Solid State Ionics 53 (1992), 1059.

[27] V. Bekiari, G. Pistolis, and P. Lianos, Chem. Mater. 11 (1999), 3189.

[28] K. Dahmouche, M. Atik, N. C. Mello, T. J. Bonagamba, H. Panepucci, P. Judeinstein, and M. A. Aegerter, Solar Energy Mater. and Solar Cells 54 (1998), 1.

[29] M. S. Vong, N. Bazin, and P. A. Sermon, J. Sol-Gel Sci. Techn. 8 (1997), 499.

[30] K. Nishio, K. Okubo, Y. Watanabe, and T. Tsuchiya, J. Sol-Gel Sci. Techn. 19 (2000), 187.

[31] E. Stathatos, P. Lianos, U. Lavrencic-Stangar, B. Orel, and P. Judeinstein, Langmuir 16 (2000), 8672.

[32] E. Stathatos, P. Lianos, P. Falaras, and A. Siokou, Langmuir 16 (2000), 2398.

[33] E. Stathatos, T. Petrova, and P. Lianos, Langmuir (2001), submitted.

[34] I. Ilisz and A. Dombi, Appl. Catal. A: General 180 (1999), 35. 
[35] J.-M. Herrmann, H. Tahiri, Y. Ait-Ichou, G. Lassaletta, A. R. Gonzales-Elipe, and A. Fernandez, Appl. Catal. B.: Enviromental 13 (1997), 219.

[36] G. Zhao, H. Kozuka, and T. Yoko, Thin Solid Films 277 (1996), 147.

[37] G. Lassaletta, A. R. Gonzales-Elipe, A. Justo, A. Fernandez, F. J. Ager, M. A. Respaldiza, J. G. Soares, and M. F. Da Silva, J. Mater. Sci. 31 (1996), 2325.

[38] H. Tada, K. Tiranishi, Y.-I. Inubushi, and S. Ito, Langmuir 16 (2000), 3304.
[39] C. Wen, K. Ishikawa, M. Kishima, and K. Yamada, Solar Energy Materials and Solar Cells $\mathbf{6 1}$ (2000), 339

[40] M. Ihara, K. Tanaka, K. Sakaki, I. Honma, and K. Yamada, J. Phys. Chem. B 101 (1997), 5153

[41] G. Zhao, H. Kozuka, and T. Yoko, Solar Energy Materials and Solar Cells 46 (1997), 219. 


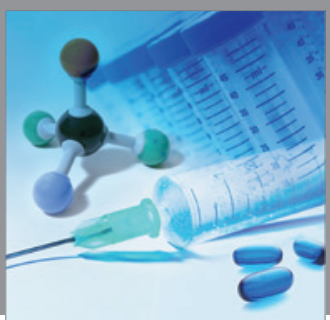

International Journal of

Medicinal Chemistry

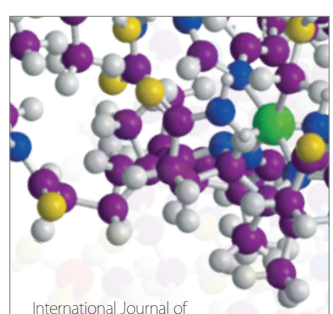

Carbohydrate Chemistry

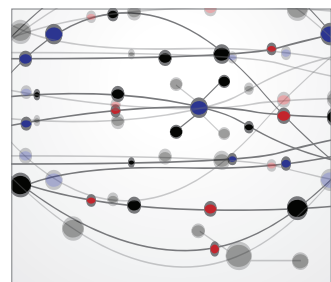

The Scientific World Journal
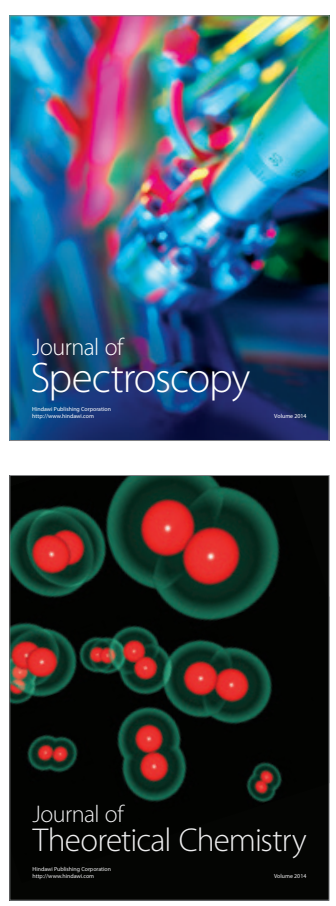
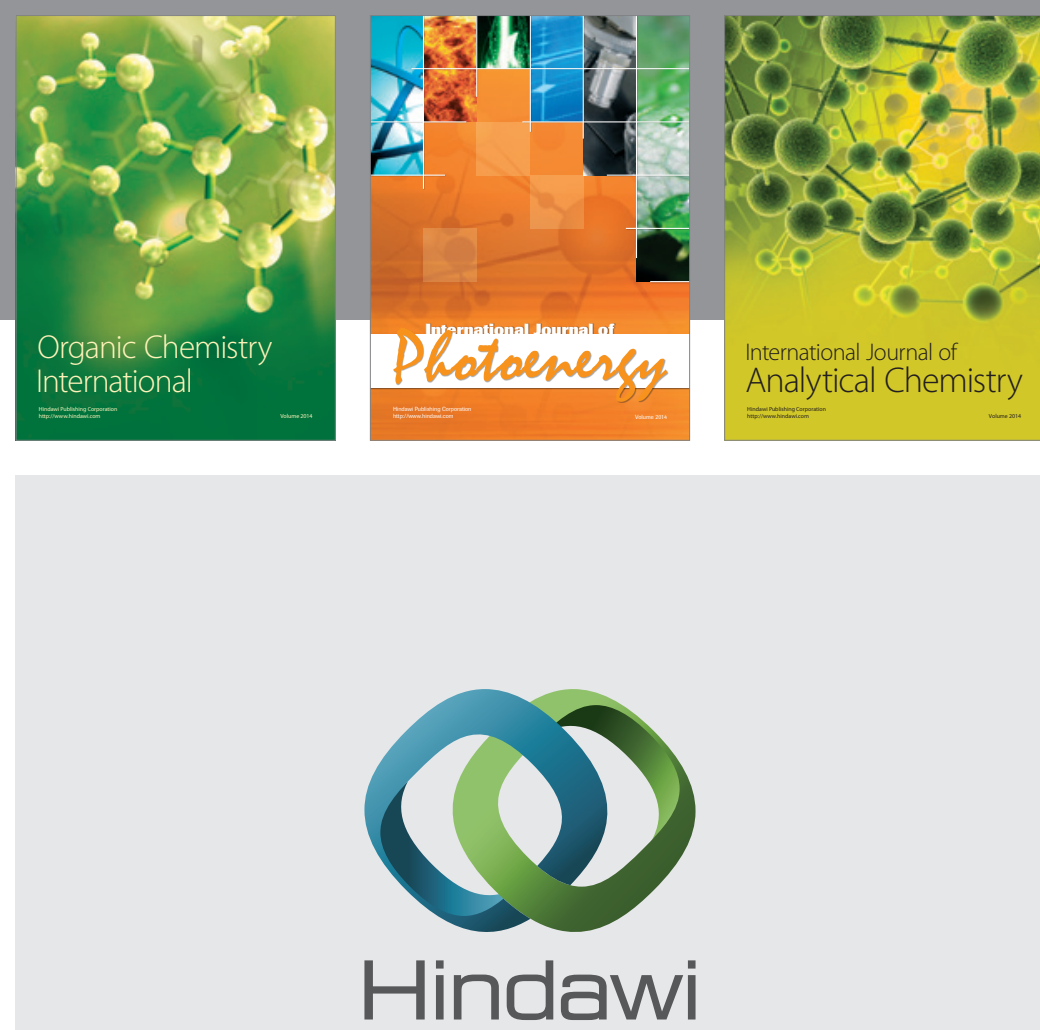

Submit your manuscripts at

http://www.hindawi.com
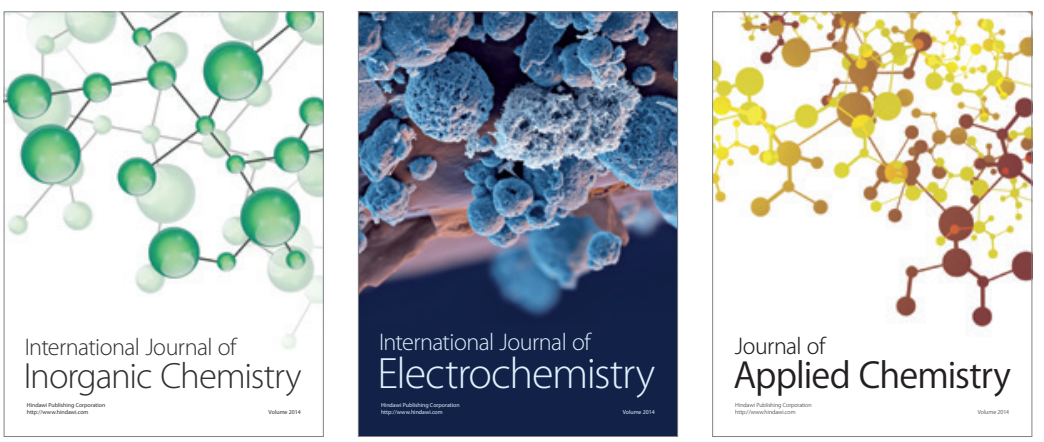

Journal of

Applied Chemistry
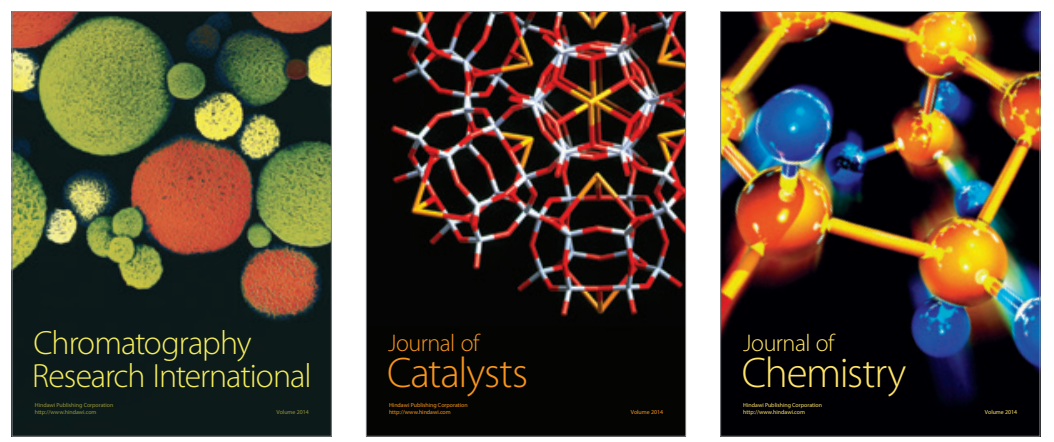
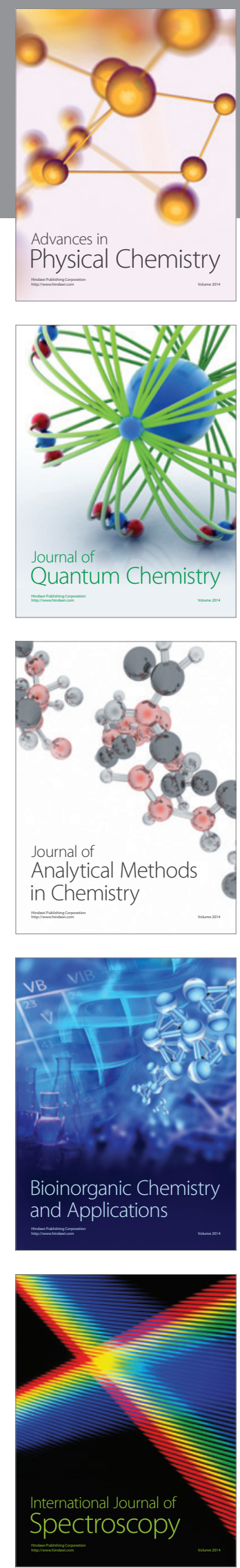